longitudinal groove; the whole of the track lodging the umbilical vein. At the back part of the right end of the liver the inferior cava enters, and, bending to the left, margins the posterior border of the organ previous to passing through the diaphragm. The situation of the supra-renal capsules, $G$, has been alluded to; they bear their usual relative proportion to the kidneys. - Urinary organs: The kidneys, H, are placed immediately below the supra-renal bodies, and are unusually lobulated, from the projection at their surface of numerous contained cysts. The right ureter, $I$, is much convoluted upon itself; becoming larger as it descends, and forming below a dilatation the size of a nut, which rests upon the cxcum, F, through the walls of which a contracted continuation of it passes obliquely to open within. The left duct presents more curves than its fellow, and below becomes suddenly lessened in size to form a slender tube, which has also its valvular termination in the crecum. The pancreas is small. The spleen, D, normally placed as regards the stomach, is round, and nearly two inches in length.-The Stomach, $\mathbf{C}$, is situated immediately below the centre of the liver, and is like the remainder of the alimentary canal to as far as the cæcum; in all respects well formed. On the left side of, and near the upper wall of the cæcum, the small intestines terminate by an opening having an oblique direction, into the cavity of the former, $\mathrm{E}$. The mesentery is very long.-Cocum, $F$ : the size of the opening into this cloaca, as it may be termed, is that of the circumference of a small orange; its cavity is large, having the right half lined by perfectly smooth mucous membrane, whilst on the left side this membrane presents a continuous series of complex ruga. The walls present several openings, thus-one on either side for the ureters; one on the left for the ileum, behind and to the left of which is an aperture leading to a convoluted appendix vermiformis, and in front of this is the mouth of a little pouch, a supplemental appendix, which projects from the upper wall of the cavity. More posteriorly, this wall juts out to form a cul-de-sac, about lialf an inch in length, and which represents the commencement of the ascending colon. The remainder of the large intestine is wanting. At the posterior part of the cloaca is a puckered surface of the size of a sixpence, covered by perfectly-formed skin, and to the left of it projects a small, tongue-shaped process of the mucous membrane, having immediately above it a valvular aperture, which leads directly backwards into the uterus.-Generative organs: There was an entire absence of the external parts, with the exception of the process just spoken of, which might have represented a clitoris; behind this, an oblong body projected immediately backwards, beneath the extremity of the coccyx (which was turned abruptly forwards), and its fundus protruded into the cavity of the spina bifida. It was evidently the uterus, having rather a large space within, and giving attachment to three fleshy, nipple-like eminences. The termination of the cavity was by the orifice placed directly above the tongue-shaped process at the back of the cloaca; the ovaries could not be distinguished-Thorax: The situation of the heart, $A$, which was contained in its pericardium, has been referred to. The organ itself was in all respects natural, but the vessels at its base were abnormally long. The ductus arteriosus was also elongated, and somewhat curved. The shape of the lungs was in accordance with the deformity of the chest. The thymus gland natural.- The arteries: The aorta just below the diaphragm gave off an axis which immediately divided into the hepatic, supra-renal, and renal arteries. The hepatic was remarkably small for the bulky part it supplied. The arteries of the stomach and duodenum were offsets from the mesenteric vessels, which were three in number, and arising close together from the aorta; by them the small intestines and cacum were supplied; the inferior mesenteric was absent. The aorta, having pursued the course of the curved spine for a short distance, sent off a small artery obliquely downwards, and to the left under the kidney and ureter, to become the femoral; an inch lower down it furnished an equally small right femoral, whilst the continuation of the aorts, scarcely diminished in size, turned upwards and forwards by the right side of the cæecum, to join the umbilical vein in the funis.-The Veins: The nmbilical vein, curving upwards by the side of the cæcum, entered the posterior part of the fissure between the lobulus Spigelii and left lobe of the liver, and, turning to the right side, passed into the longitudinal groove, which, conducting it to the transverse fissure, it there joined the left branch of the vena portæ-or, rather, the one vessel became directly continuous with the other. The vena cava received a trunk just below the liver, formed by the junction of the left femoral vein, left ileo-colic, supra-renal, renal, and ureteric veins. The veins of the left side of the cloaca accompanied their arteries, and formed two vessels, one entering the cava below that from the opposite side, whilst the other joined the main trunk a little above Poupart's ligament. The right capsular, renal, and ureteric veins, coalesced to form one vessel, which emptied itself into the cava below the preceding ones. The main trunk now passed to the posterior part of the right end of the liver, into the substance of which it plunged, and then turned abruptly to the left, so as to margin the posterior border of the organ, and received in its course numerous hepatic veins. The vena portæ was formed in the usual manner, and passed to the transverse fissure of the liver, where the left branch became, as before stated, continaous with the umbilical vein. The portal vein itself was very small, and seemed rather to empty itself into the large umbilical vein which ran across the fissure; the ductus venosus was wanting.-The skeleton: The head, neck, and upper limbs are naturally formed. The lower part of the dorsal portion of the spine becomes suddenly concave forwards, and thence, to the last coccygeal bone, the column is convex anteriorly. From these peculiarities, the tip of the coccyx is a little above and behind the symphysis pubis. The spine, from the last dorsal vertebra, is bent, also to the right, and is open behind to the same extent, from an absence of the laminæ and spinous processes. The ribs are eleven on each side, and four of those on the left are anchylosed together. The thorax is materially altered from its natural form, in consequence of the latter circumstance, and the condition of the spine. The lowermost of the right ribs touches the corresponding crista ilii. The distortion of the pelvis is considerable, from the meeting of the spinous processes of the ischium, and coalescence of the rami of the pubes, ischium, and tuberosities of the latter. The size of the pelvic cavity is so lessened, that it will contain nothing larger than a pea, and is filled with fat and cellular tissue. The iliac bones are twisted backwards, and the dorsal aspect of each is directed towards its fellow. The femora are turned upon their axes, and the great trochanters are nearly in contact. The acetabula are only slightly developed, and each femur is dislocated on to the dorsum ilii. The bones of the thigh and leg are properly formed, as are the knee-joints, but, from the position of the femora, the natural aspect of the articulation is reversed. The feet are flexed at the ankle and tarsal joints, and, at the same time, by the union of the soft parts forming the soles, they are bent forwards and twisted to the right. The ossa calcis are united together; the toes are perfect in form and number.

St. Martin's-lane, Sept. 1849 .

\section{ON THE USE OF}

ERGOT OF RYE IN THE THIRD STAGE OF LABOUR, AND THE TREATMEN'T OF HOURGLASS CONTRACTION OF THE UTERUS.

By S. MONCKTON, M.B. \&c., Brenchley, Kent.

"Quot homines, tot sententix."

In The Lancet for June 16 is a paper by Dr. M'Gregor, upon "The Use of the Secale Cornutum in the Third Stage of Labour," on which, if comparative inexperience did not render it somewhat presumptuous on my part, I would pass the stricture once applied by Blumenbach to the then nascent system of phrenology:- "Herein do I discover much that is new and much that is true; but, unfortunately, the new is not true, and the true not new." The profession at large is well aware that the applicability of ergot does not cease with the birth of the child; that circumstances may arise to render its exhibition both hopeful and appropriate after this period; but I do think experience generally would tend to circumscribe within much narrower limits than those assigned by $\mathbf{D r}$. M'Gregor, the class of cases likely to require, or be benefited by, the employment of ergot in the third stage. Premising, Sir, that these observations are really penned in a candid and liberal spirit, I will, with your permission, offer a few remarks on some portions of the paper in question.

The use of ergot in the first stage is spoken of, more than once, as orthodox and beneficial. Allow me to suggest a doubt of its being either one or the other. Dilatation of the os uteri is a two-fold process, comprehending, in addition to the tensive and expanding efforts of the womb, more or less of gradual and active resolution in the tissue of the os itself, precisely analogous to that softening and relaxation that we find to take place in the os externum and vagina, before any mechanical distention, by head or otherwise, has been brought 
to bear upon them. If this preparation be incomplete-i.e., if the os be still dense and indisposed to yield, the exhibition of ergot will be dangerous. Time alone, under ordinary circumstances, time and opium where there is much irritability, are the indications where, on the other hand, the os uteri has been so far relaxed as to require for its expansion the lightest touch only of the fingers or the head. The first stage may, in fact, be regarded as complete, and a dose of ergot sometimes be admissible, with a view to accelerating the commencement of the second.

The doctor then proceeds to recommend its employment in the three following cases, where we have retained placenta, from inaction, irregular contraction, or morbid adhesions. Simple inaction is so readily overcome, after a few minutes; rest, by a slight traction of the cord and titillation of the os, with one hand; and a simultaneous but gentle compression of the uterus, with the other; that no possible necessity appears to exist for the introduction of a different practice. If the inaction depend upon sluggishness, we supply in this way, what alone the ergot can give-a stimulus-if, upon exhaustion, we afford likewise assistance and support. The employment of the hand, too, has another decided advantage over that of the drug, inasmuch as the amount of interference may be, and is, adjusted to the requirements of the case-from the simple ascertaining that "all is right" to the active removal and firm compression required in hæomorrhage. The ergot will most likely do nothing; but it may inflict many hours' unnecessary pain. I do not say that in these cases, hæemorrhagic or otherwise, it should not be made use of as an adjunct; on the contrary, I very frequently employ it myself; but I do submit that the man is foolish who relies upon it much, and culpable who trusts it alone. Dr. M'Gregor appears to overrate, and that considerably, the pain and ineligibility of the manual process, a portion of which must be gone through, even if we employ successfully the ergot of rye. The custom of awaiting for three hours the natural expulsion of the secundines is, too, so singularly foreign to the ideas and practice of myself and medical neighbours, that we really seek in amazement some proofs of its propriety or advantage - a quest assuredly not satisfied by the cases of Dr. $\mathrm{M}^{\epsilon} \mathrm{Gregor}$, wherein it appears that his time and the woman's blood were alike sacrificed, simply for the purpose of employing, after the lapse of some hours, means equally available in the first instance.

The question of hour-glass and irregular contraction is one of much importance, from its probable connexion with many cases of severe hæmorrhage, and nnfortunately requires for its discussien a larger amount of experience and observation than I can bring to bear upon the subject.

Any amount of spasm occurring so as to retain and incarcerate the whole placenta, or even the greater portion of it, appears to be always located in the os and cervix; and I have observed it repeatedly in connexion with a certain series of antecedents, in this way. There will be, in the first instance-i.e., in the first stage, an unusual amount of substance, tonicity, and resistance about the os and cervix; the liquor amnii is discharged early, from the natural activity of the uterus; the employment of ergot; the interference of the accoucheur; pushing up the edges of the os over the head, and so forth; or from some similar cause the head at last enters the aperture suddenly, and the os becomes impalpable -here ensues a little delay. The pains are active, the passage is free; but the advance of the head is not proportionate, because it is gripped from the chin round to the occiput by the lower fibres of the uterus, which in this way counteract the pressure of its superior portion. Presently the head does sweep the pelvis, and is again delayed at the os externum, not from any actual impediment in this situation, but from a transference of the stricture to the body and shoulders. Shortly, however, with slight assistance, the child is expelled per saltum, the cord appearing to be very short. In a few minutes, unless prepared by these consecutive phenomena, the accoucheur, on attempting to glide his fingers up the cord, is astonished to find all access to the placenta cut off by firm annular contraction. How, then, is he to proceed? If he can insinuate two or three fingers, let him do it, (in any case, I think, at once-assuredly so if there be hæemorrhage, keep up a dilating effort, disregard the root of placenta, and lodge some portion of the edge upon the palmar surface of his fingers; with a little coaxing of this description you can extrude the placenta by pressure from without as you would the contents of an atheromatous tumour. This is always a proceeding of some pain and difficulty, but in my little experience-half-a-dozen cases-it has never proved so to any remarkable extent.
Many other points might deserve mention, but I merely allude to, without pretending to describe, the execution of this particular office. Once in my hands, when used experimentally, the ergot proved a signal failure. After a sequence of preliminaries as above described, occurring in a tradesman's wife, I found myself confronted by a very close, convulsivei. e., irritable-stricture, pretty high up, without hæmorrhage, and no portion of the placenta to be touched. The pains being unusually regular and active, I determined to see what half an hour would bring forth; this proved to be nothing. I then administered a full dose of secale cornutum, which induced, during the next half-hour, severe and almost unceasing uterine efforts; finding, still, placenta, stricture, \&c., precisely in statu quo, I gave nearly a drachm of laudanum, (this was just prior to the appearance of chloroform upon the stage,) and with extra caution, the fibres being irritable, soon employed successfully the ordinary manual method. What effect a repetition of the ergot might have had in a few hours, or the next day, I am not prepared to determine; if you employ patience as a vehicle for your medicine, opium doubtless deserves the preference.

There is another form of partial contraction incident to the uterus not so readily recognised by vaginal examination, but manifesting itself as a lobnlated, uneven surface, to be felt above the pubes, instead of the ordinary globose figure of the uterus. To this condition, or a parallel one, I presume Dr. M'Gregor alludes. Gentle moulding and steady compression appear to be the remedies. There seens some ground for the apprehension that an early exhibition of ergot in such a case would be quite as likely to irritate and keep up the already existing local spasms as it would be to make them "merge into a general contraction of the entire substance." First model and reduce the uterus, then promote its firmness and further diminution by ergot if you like.

Upon the subject of morbid adhesions, again, much already said might be repeated, when really nothing but the skilful and deliberate employment of the fingers, or, failing this, the solvent action of incipient putridity, can avail us. Irritation, compression, and ergot, may assist, and ought to be employed; on the whole, adhesion of placenta is a condition much more frequently spoken of than met with. I have never seen it except to a very limited extent, involving, perhaps, one coty. ledon; and Dr. M'Gregor must pardon my suggesting a doubt as to the nature of his case No. 1 , which was probably one of partial separation without allhesion at all.

As an epitome, then, of the claims of ergot, I think we may venture to assert, that in every six instances of its employment it will be in two needless, and in two useless; in one more, perhaps efficient only as an adjuvant, or by performing for us what we might equally well have performed without it. Its capability of acting appears to diminish in a direct ratio with the increase of necessity for its doing so; when the uterus is acting, or disposed to act, this drug will frequently augment its efforts; when the organ is thoroughly inert, the drug appears to be so likewise. Let the womb be lax, the functions failing, blood flowing, and woman fainting, and ergot will almost never stand you in stead. After other, and far more energetic, treatment has fairly arrested the chariot of death, it is a satisfaction, and may be an advantage, to maintain contraction by a full dose, to induce the uterus, in this way, by progressive efforts, to withstand the impulse of the rising circulation.

These very thoughts have often occurred to me with reference to another expedient, eloquently advocated by Dr. Rigby, -application of the baby to the breast; once get an urgent case, in which the resource would be really valualle, and you are sure to find the infant dead or refusing to suck; the breasts inacessible for stays and envelopes; the woman insensible to mental emotions, or the uterus not susceptible of its wonted sympathy. In fine, both plans are striking and feasible enough to enunciate, but, in too many instances, like Mokanna's miracles, they lack to be true.

Brenchley, Kent, Sept. 1849.

\section{COMMUNICATIONS ON THE TREATMENT OF CHOLERA.}

On the Treatment by Repeated Doses of Calomel.

By J, H. Nankivelu, Esq., M.R.C.S., St. Columb, Cornwall. WHeN cholera first appeared in this county in 1832, I had an opportunity a seeing abont forty cases in the practice of Mr. Cornish, at Falmouth, and he very soon found that calo- 